\title{
Chiral gold-PPA nanocomposites with tunable helical sense and morphology
}

Julián Bergueiro, Manuel Núñez-Martínez, Sandra Arias, Emilio Quiñoá, Ricardo Riguera and Félix Freire

\section{Accepted Manuscript}

\section{How to cite:}

Nanoscale Horiz., 2020, 5, 495

\section{Copyright information:}

(C) The Royal Society of Chemistry 2020. This article may be used for non-commercial purposes in accordance with RSC Terms and Conditions for Use of Self-Archived Versions 


\title{
Nanoscale Horizons
}

\section{COMMUNICATION}

Received 00th January 20xx, Accepted 00th January 20xx DOI: $10.1039 / x 0 \times x 00000 x$

www.rsc.org/

\section{Chiral Gold-PPA Nanocomposites with Tunable Helical Sense and Morphology}

\author{
Julián Bergueiro ${ }^{\ddagger}$, Manuel Núñez-Martínez ${ }^{\ddagger}$, Sandra Arias, Emilio Quiñoá, Ricardo Riguera and Félix \\ Freire*
}

\begin{abstract}
A novel type of stimuli-responsive dynamic helical polymer-metal nanoparticle nanocomposite formed by a helical poly(phenylacetylene) (PPA) combined with gold nanoparticles (AuNPs) is described. Thus, several PPA copolymers containing the ethynyl-4-benzamide of $(S)$-phenylglycine methyl ester (M1) to dictate the helical structure/sense of the copolymer, and the ethynyl-4-benzamide of the 11-((2-(2-(2-aminoethoxy)ethoxy)ethyl)amino)undecane-1-thiol (M2) to link the copolymer to the AuNPs are prepared. Different morphologies of these nanocomposites were obtained by considering the thiol ratio and the self-assembly properties of the PPA, which generates from dispersed AuNPs until fibre like structures. All these nanocomposites show a dynamic chiral behaviour, being possible to manipulate their helical sense by the action of external stimuli. Moreover, it is possible to control the aggregation of these nanocomposites into macroscopically chiral nanospheres with low polydispersity by using $\mathrm{Ba}^{2+}$ as crosslinking agent.
\end{abstract}

\section{Introduction}

Hybrid nanomaterials ${ }^{1,2}$ had become a very important area in nanoscience thanks to the synergistic combination of the properties of their building blocks. In this way, new nanoengineered materials with morphological diversity and potential applications in photonics, ${ }^{3}$ optics, ${ }^{4}$ asymmetric catalysis, $^{5}$ selective separation, ${ }^{6}$ chiral sensing and recognition ${ }^{7}$ and drug delivery, ${ }^{8}$ have been described.

Gold nanoparticles (AuNPs) have been widely employed as inorganic building blocks to form these nanocomposites. This is due to their plasmon related unique optical properties that facilitate applications like fluorescence, surface enhance Raman spectroscopy (SERS), ${ }^{9-11}$ phototransducers in photothermal therapy (PTT) ${ }^{12-13}$ and ultrasound among others. Moreover, the easy surface modification of the AuNPs with thiolated organic molecules allow their functionalization and the production of a variety of nanomaterials. ${ }^{14-16} \mathrm{As}$ organic building blocks to form these kind of nanocomposites different chiral small molecules, supramolecular polymers and natural

Centro Singular de Investigación en Química Biolóxica e Materiais Moleculares (CIQUS) and Departamento de Química Orgánica, Universidade de Santiago de Compostela, 15782 Santiago de Compostela, Spain.

E-mail:felix.freire@usc.es

† Footnotes relating to the title and/or authors should appear here.

Electronic Supplementary Information (ESI) available: [Materials and methods, Names and Codes, Synthesis of monomers, Synthesis Homo-and Copolymers, Thermal studies for copolymers, CD and UV.Vis studies for copolymers, Synthesis of Gold Nanoparticles, Thermal studies for Nanoparticles, CD and UV-Vis studies for nanocomposites, Microscopy studies for Nanocomposites, Supporting references]. See DOI: 10.1039/x0xx00000x biomacromolecules such as proteins, RNA or DNA were used in combination with AuNPs. ${ }^{17-18}$ From these studies, only a very limited number of reports employed chiral synthetic polymers for this purpose. ${ }^{19}$ Moreover, in most of the AuNPs based nanocomposites reported, the chiral coating of the AuNPs, is static. This means that the helix of the biomolecule (protein, DNA, polymer) constituting the coating, is not altered -inverted or enhanced- by the formation of the nanocomposite. An important breakthrough in this aspect has been recently presented by Prof. Zhao et. al. They showed that the chirality of a hybrid material composed by an organogelator and AuNPs can be tuned by manipulation of the coordination of the organogelator to the $\mathrm{Au}(\mathrm{III})$ atoms, before the formation of the gold nanoparticles. ${ }^{20}$

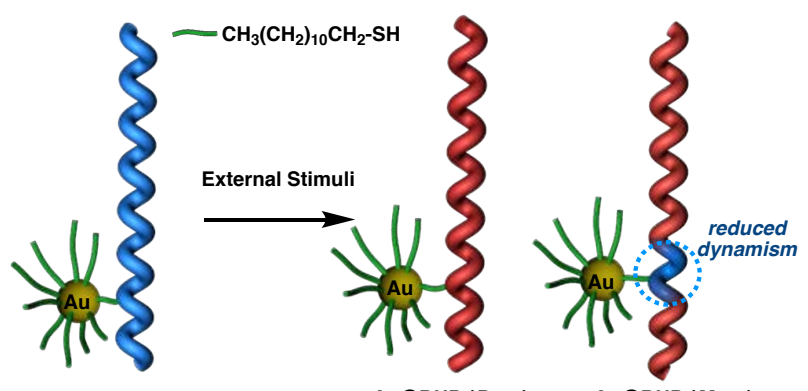

Au@DHP $\left(M_{\text {helix }}\right)$

Au@DHP $\left(P_{\text {helix }}\right)$

Au@DHP $\left(M_{\text {helix }}\right)$

Scheme 1. Conceptual representation of Au-DHP nanocomposites with a dynamic chiral soft component.

Herein, we describe how the combination of AuNPs with dynamic helical polymers (DHP) ${ }^{21-24}$ produces new nanocomposites with tunable helical sense, and nanoaggregates with controlled size and morphology 
(Scheme 1). We reasoned that the use of preformed helical thiolated copolymers in the synthesis of hybrid materials would allow us to achieve a better control over the morphology of the nanocomposites obtained. Thus, by tuning the amount of thiolated monomer within the copolymer it is possible to control the number of connecting points towards the AuNPs surface. Moreover, considering the helical structure defined by the helical copolymer, it is expected that the different thiol groups point to different directions from the helix (Figure 1). Furthermore, the metal nanoparticles can be used to crosslink different polymer chains, fact that is favored by the different spatial orientation of the thiol groups within the helical structure. As a result, nanocomposites with different morphologies should be obtained.

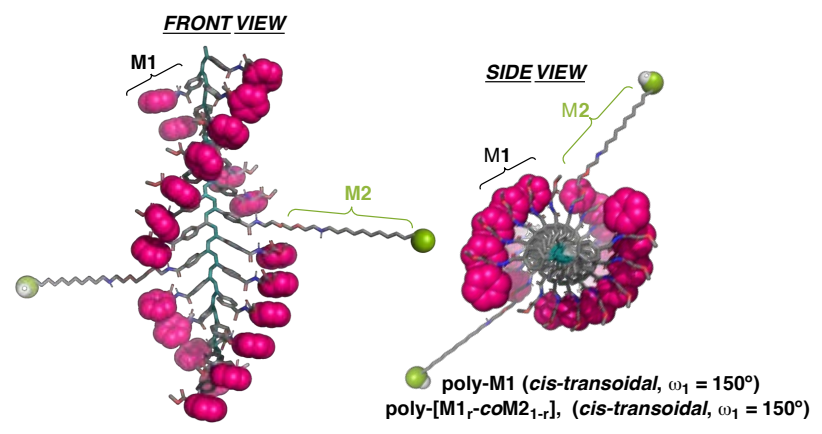

poly-M1 (cis-transoidal, $\omega_{1}=150^{\circ}$ )

poly-[M1 $1_{\mathrm{r}}$-co-M2 $\left.1_{-\mathrm{r}}\right]$, (cis-transoidal, $\omega_{1}=150^{\circ}$ )

Figure 1. Graphic illustration of the potential helical structure adopted by poly-[M1 $\left.1_{r}-\mathrm{CO}-\mathrm{M} \mathbf{2}_{1-r}\right]$ highlighting the possible distribution of monomer 2 within the helix scaffold.

\section{Results and Discussion}

As organic component of the composite, we chose poly(phenylacetylene) $\mathrm{s}^{25-33}$ (PPA)s PPAs bearing amino acid residues as substituents. This class polymers adopt helical structures where the $P / M$ helix is stabilized by hydrogen bonds between neighboring pendants $-n^{\text {th }}$ and $(n+2)^{\text {th }}$ or $\mathrm{n}^{\text {th }}$ and $(\mathrm{n}+3)^{\text {th }}-$ which are arranged into a $\beta$-sheet like orientation. ${ }^{34}$ Nevertheless, external stimuli that modify the conformation of the pendants or their hydrogen bonding are known to produce relevant structural changes - helix inversion and/or elongation - ${ }^{35-41}$ The preparation of the Au-PPA nanocomposite requires the presence in the PPA polymer of thiol groups necessary to link the PPA to the metal nanoparticle. Thus, we decided to use a copolymer composed by a major component designed to keep the helical structure and its response to the stimuli and another co-monomer that bears a thiol group to link the PPA to the metal nanoparticle (minor component).

In this way, we selected the 4-benzamide of the phenylglycine methyl ester (M1) as the comonomer that controls the helical structure and the 4-benzamide of the 11-((2-(2-(2-aminoethoxy)ethoxy)ethyl)amino)undecane-1thiol (M2) as the component designed link to the gold (Figure 2).
The polymerization of the mixture $\mathrm{M} 1-\mathrm{M} 2$ in the final copolymer poly-(M1 $\left.\mathbf{1}_{\mathrm{r}}-\mathrm{CO}-\mathrm{M} \mathbf{2}_{1-\mathrm{r}}\right)$ was determined by NMR. All copolymers were fully characterized by NMR, UV, CD, IR, Raman, TGA, DSC and GPC (See ESI).

The concentration of thiolated groups in the copolymers was found to have a strong effect on the solubility of the material and in fact, only insoluble gels are obtained when the molar fraction of $\mathrm{M} 2$ is higher than 0.05 , probably due to the formation of inter chains disulfide bonds. Therefore, we selected for our study copolymers with a thiol molar fraction in the range of 0.01 to 0.05 and explored measures to avoid thiol oxidation during the synthesis and purification. The following two synthetic approaches were examined and compared:

1) Copolymerization of M1 with the unprotected thiolated monomer $\mathbf{M} 2$ in the presence of TIPS-SH to avoid thiol oxidation (See ESI for details) (route 1).

2) Copolymerization of $\mathrm{M} 1$ with the trityl protected monomer M2, followed by deprotection of the resulting copolymers with TFA/TIPS-SH (See ESI for details) (route 2).

Thus, copolymers poly-( $\left.\mathrm{M} \mathbf{1}_{0.99}-\mathrm{Co}-\mathrm{M} \mathbf{2}_{0.01}\right)$; poly-( $\mathrm{M} \mathbf{1}_{0.98}-\mathrm{CO}-$ $\left.\mathrm{M} \mathbf{2}_{0.02}\right)$; poly-(M1 $\left.\mathbf{1}_{0.97}-\mathrm{CO}-\mathrm{M} \mathbf{2}_{0.03}\right)$; poly-( $\left.\mathbf{M 1}_{0.96}-\mathrm{CO}-\mathrm{M} \mathbf{2}_{0.04}\right)$, and poly-( $\left(\mathbf{1}_{0.95}-\mathrm{CO}-\mathrm{M} \mathbf{2}_{0.05}\right)$ were prepared allowing us to study by $C D$ the influence of the two different approaches and comonomers over the net PPA helicity. These studies revealed that the trityl protected copolymers (method 2) present practically the same $C D$ as the parent homopolymer poly-M1. This fact indicates that the introduction in the main chain of the (Trt)-M2 protected monomer at low comonomer ratios does not affect the helical structure determined by the chiral phenylglycine monomer M1. In contrast, the copolymers obtained using the unprotected M2 (method 1) present with respect to poly-M1, an important helix decay of around $40-50 \%$. This fact indicates that the introduction of the thiolated comonomer in the main chain, produce some destabilization of the helical arrangement. This helical disturbance should occur nearby the thiolated group within the copolymer chain, and therefore should depend on thiol group ratio. Nevertheless, the depletion of the helical folding is practically the same within 0.01 to 0.05 molar fraction, suggesting that perhaps the thiolated groups are not randomly distributed but somehow accumulated likewise in a block copolymer.

Alternatively, when the (Trt)-M2 protected copolymers were deprotected with TFA $(1 \% \mathrm{v} / \mathrm{v})$, an $80 \%$ reduction of the $C D$ trace was observed. Poly-M1 is perfectly stable in those conditions (see ESI), therefore, the TFA deprotection of $\mathrm{M} 2$ is the factor that triggers this important loss of helical preference. In any case, this unfolding renders useless for our purpose the copolymers prepared by the protection/deprotection approach. Therefore, we centered our studies on the copolymer series obtained by direct polymerization of comonomers M1 and M2, which conserve a significant helical preference. 


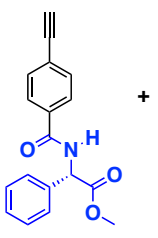

M1

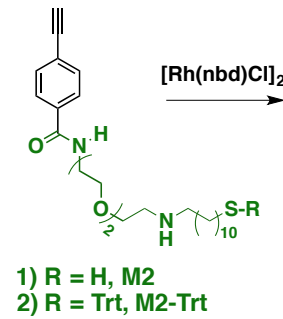

1) $R=H, M 2$
2) $R=$ Trt, M2-Trt

Figure 2. Synthesis and structure for poly-(M1 $\left.\mathbf{1}_{\mathrm{r}}-\mathrm{CO}-\mathrm{M} \mathbf{2}_{1-\mathrm{r}}\right)$ copolymers series.

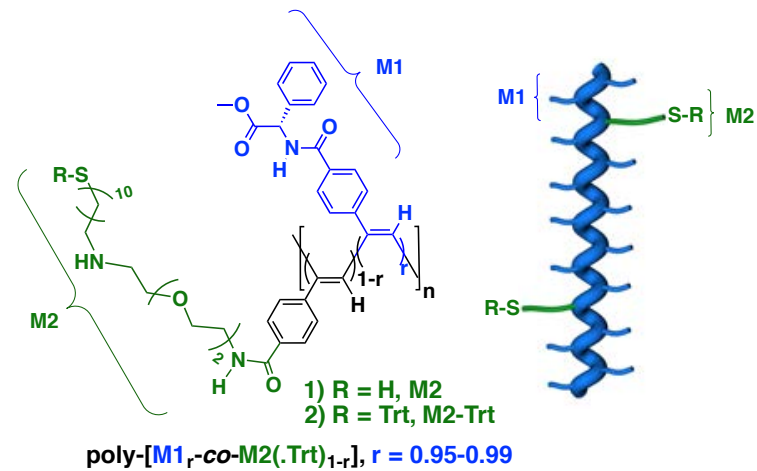

poly-[M1 ${ }_{\mathrm{r}}$-co-M2(.Trt) 1-r $\left._{\mathrm{r}}\right], \mathrm{r}=$ 0.95-0.99
Structural studies - DSC, CD, UV (see ESI) - on the poly$\left(\mathrm{M1}_{\mathrm{r}}-\mathrm{Co}-\mathrm{M2}_{1-\mathrm{r}}\right) \quad(\mathrm{r}=0.99-0.95)$ series indicated that copolymers containing thiolated units conserve the helical structure commanded by monomer M1, in poly-M1 (CD (-), $\left.M_{\text {helix }}\right)$, and that the folded part of the chain adopts the same cis-transoidal helical scaffold.

In addition, these copolymers respond to stimuli such as solvent polarity and $\mathrm{Li}^{+}$ions ${ }^{43-44}$ as the parent homopolymer M1. Thus, the series poly-(M1 $\left.1_{r}-C o-M 2_{1-r}\right)(r=0.99-0.95)$, were shown to invert their helical sense by polarity changes of the solvent or by addition of $\mathrm{LiClO}_{4}$ (Figure 3c and ESI).
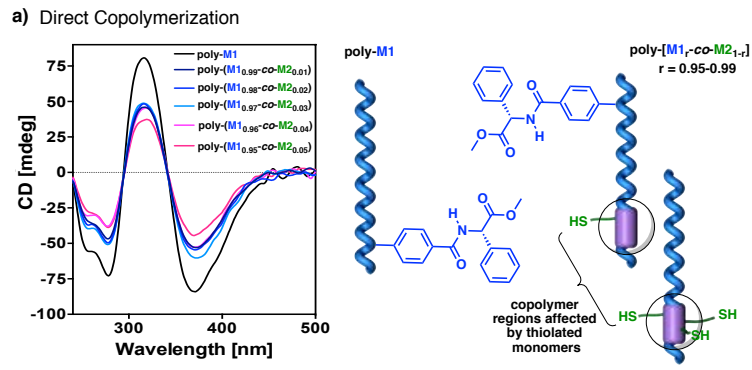

b) Deprotection of a preformed protected copolymer
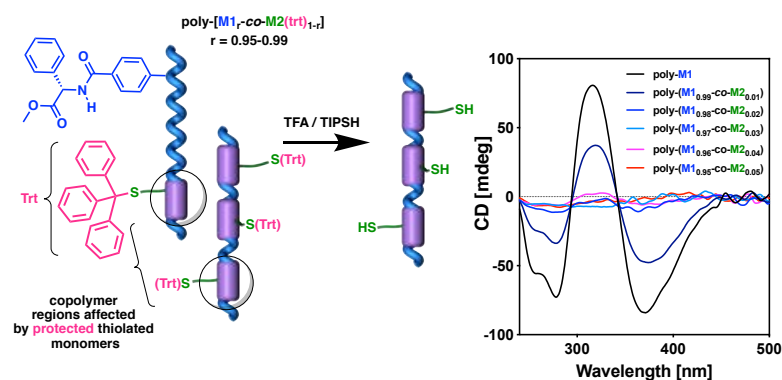

c)
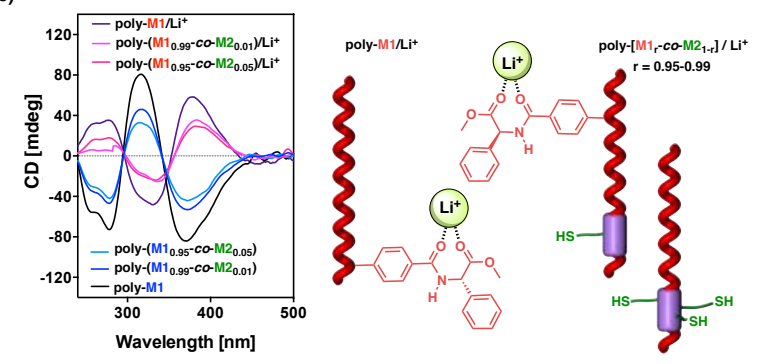

Figure 3. Comparative $C D$ values for poly-M1 and poly- $\left(\mathrm{M} \mathbf{1}_{\mathrm{r}}-\mathrm{CO}-\mathrm{M} \mathbf{2}_{1-\mathrm{r}}\right)$ copolymers $(r=0.99-0.95)$ prepared by $(a)$ direct synthesis or (b) by a protection/deprotection approach. $\mathrm{c}$ ) Dynamic behavior of poly-M1 and
poly-(M1 $\left.1_{r}-c o-M 2_{1-r}\right)(r=0.99-0.95)$ obtained by direct copolymerization after
the addition of $\mathrm{LiClO}$. the addition of $\mathrm{LiClO}$

During these studies we found that the presence of external stimuli affects the folded fragment of the polymer chain only, producing a helix inversion or amplification proportional to the folded contain of the copolymer but never reaching the levels of the parent homopolymer. For instance, the $C D$ spectra of poly-( $\left.\mathrm{M}_{0.99}-\mathrm{Co}-\mathrm{M} \mathbf{2}_{0.01}\right)$ shows with respect to poly-M1, a $40 \%$ decay and conversely, when compared to poly-M1/ $\mathrm{Li}^{+}$complex, the $\mathrm{CD}$ of copolymer metal complex poly-( $\left.\mathbf{M 1}_{0.99}-\mathrm{CO}-\mathrm{M} \mathbf{2}_{0.01}\right) / \mathrm{Li}^{+}$suffers a $40 \%$ decay too.

Once copolymers with dynamic response to stimuli were obtained, grace to comonomer M1, we tried to link the thiolated monomers $\mathrm{M} 2$ to the AuNPs. To that end, poly(M1 10.99-0.95-co-M2 $_{\text {0.01-0.05) }}$ ) were combined with AuNPs using a variation of the Brust-Schiffrin method (BS). ${ }^{42}$

Dodecanethiol was added during the nanocomposite formation to improve the stabilization of the AuNPs (see ESI for experimental details). The resulting Au-poly(M1 $\mathbf{1}_{\mathrm{r}}-\mathrm{Co}-$ $M 2_{1-r}$ ) hybrid materials were purified by precipitation, redispersion and centrifugation. Finally, the different products were further purified by gel permeation chromatography (GPC) (Figure 4 and see ESI). These nanocomposites are very stable, can be stored in solid state for months being possible to redisperse them in solution without altering their properties.

Figure 4 shows the GPC chromatograms recorded at 380 (helical polymer absorption) and $540 \mathrm{~nm}$ (nanoparticle plasmon band) for three different THF solutions containing the copolymer (solution 1), dodecanethiol@AuNPs (solution 2$)$ and the hybrid material -Au-poly-( $\mathbf{M 1}_{0.95}-\mathrm{CO}$ $\left.M 2_{0.05}\right)$-, which clearly demonstrate the formation of the nanocomposites (see ESI for the GPC data). In accordance with that, the UV spectra of nanocomposites $\left(0.7 \mathrm{mg} \mathrm{mL}^{-1}\right.$, $\mathrm{CHCl}_{3}$ ) showed the plasmon band at $520 \mathrm{~nm}$ indicating the presence of AuNPs (Figure 4d), while the CD spectra show the trace typical for a helical PPA. Therefore, these results indicate that nanocomposites are chiral, showing an excess of a helical sense in the polymer attached to the metal 
nanoparticle (Figure 4e-f and ESI). Interestingly, the formation of the composite is accompanied with a CD signal decay when compared to the corresponding parent copolymers (Figure $5 d$ and ESI). This reduction of the helical content is not related to the synthetic procedure used to prepare the nanocomposites, which does not act on the helicity of the polymer (see ESI). Therefore, the helix depletion is produced by the presence of AuNPs in the material. In our view, this helical decay could be interpreted as the result of the close proximity of the AuNPs to the helical scaffold which results in a partially distorted scaffold due to its dynamic behavior.
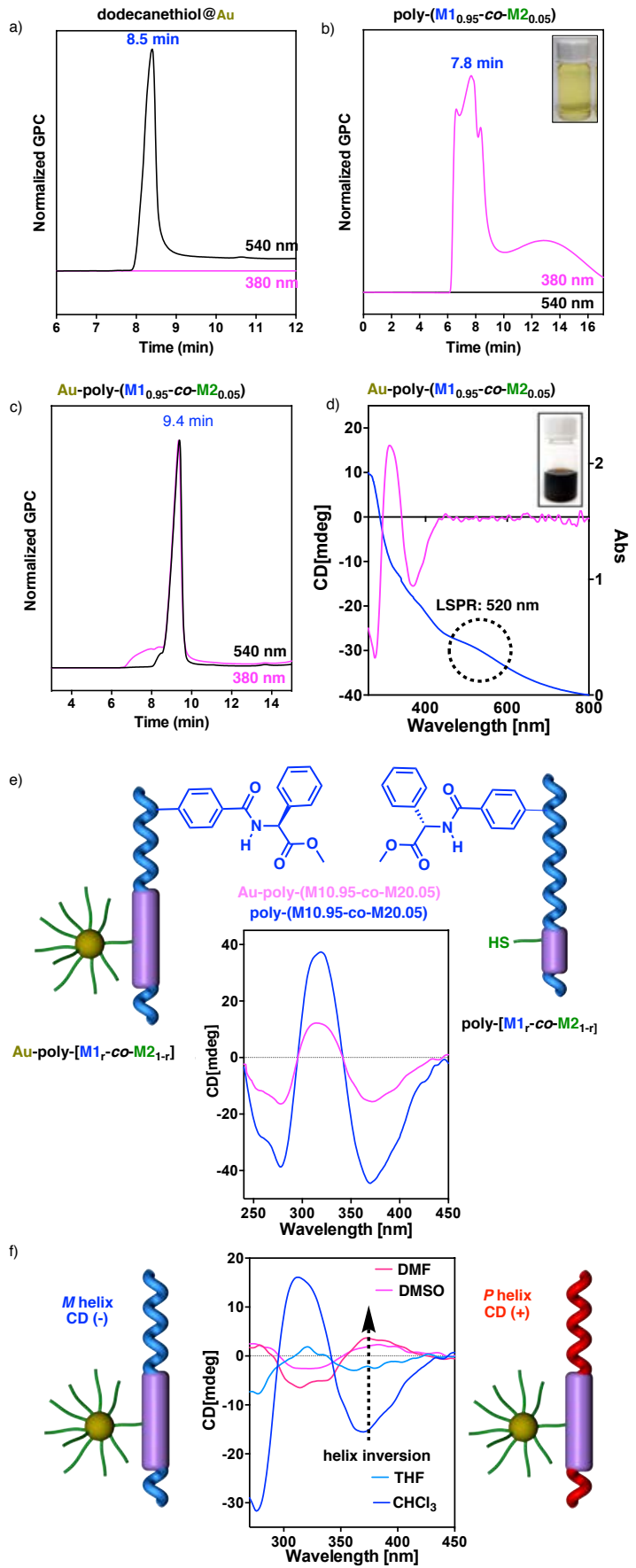

Figure 4. a) GPC chromatograms of (a) AuNPs@dodecanethiol, (b) polyand UV spectrum of Au-poly-(M1 $\left(\mathrm{M1}_{0.95}-\mathrm{CO}-\mathrm{M} 2_{0.05}\right)$ at 380 and $540 \mathrm{~nm}$. (d) $\mathrm{CD}$ and $\mathrm{CD}$ spectrum of Au-poly-(M1 $\left.\mathbf{1}_{0.95}-\mathrm{CO}-\mathrm{M} \mathbf{2}_{0.05}\right)$ in $\mathrm{CHCl}_{3} .(\mathrm{e})$ Comparison of

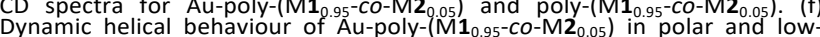
polar solvents (See ESI for experimental details).

Stimuli responsive studies on these nanocomposites reveal that these hybrid materials are dynamic and respond to the presence of external stimulus such as polarity changes (Figure 4f). Interestingly, in spite of the well-known response of the helix of poly-M1 and copolymers poly-(M1co- $\left.M 2_{1-r}\right)$ to complexation with $\mathrm{Li}^{+}$ion, the helicity of the nanocomposites is not affected by the addition of $\mathrm{Li}^{+}$salts. The same effect was observed when $\mathrm{Li}^{+}$was added to a mixture of poly-M1 and AuNPs@dodecanethiol, leading us to conclude that, for some reason, in the presence of AuNP the lithium ion is not able to complex with the polymer.

Finally, electron microscopy studies were carried out to study the morphology of the hybrid materials. SEM/TEM images showed that the morphology of the composite is directly related to the amount of the thiolated monomer in the copolymer. In this way, while composite Au-poly$\left(\mathrm{M1}_{0.99}-\mathrm{CO}-\mathrm{M} \mathbf{2}_{0.01}\right)$ is formed mainly by isolated nanoparticles that should be decorated with a single polymer chain (Figure 5), other copolymers containing larger amounts of the thiolated monomer, e. g. Au-poly$\left(\mathrm{M1}_{0.97}-\mathrm{CO}-\mathrm{M} \mathbf{2}_{0.03}\right)$, forms fibers due to the presence of more than one nanoparticle per copolymer chain (Figure 5). Thus, the Au nanoparticles are acting as crosslinking agents, bringing together several copolymer chains, which can further self-assembly by hydrogen bond interactions between pendants (Figure 5). This fact also explains the formation of a microgel in Au-poly-( $\left.\mathrm{M} \mathbf{1}_{0.95}-\mathrm{CO}-\mathrm{M} \mathbf{2}_{0.05}\right)$.

In a complementary assay, we tested the action of $\mathrm{Ba}^{2+}$ ions -known to induce aggregation on poly-M1- on the composites and it was found that -as before with $\mathrm{Li}^{+}-$the results differed depending on the thiolated contain of the copolymer. In this way, upon addition of $\mathrm{Ba}\left(\mathrm{ClO}_{4}\right)_{2}$ solution, nanocomposites with low thiol contain, produced new materials - Au-poly-( $\left.\mathrm{M1}_{0.99}-\mathrm{Co}-\mathrm{M2}_{0.01}\right) / \mathrm{Ba}^{2+}$ and Au-poly$\left(\mathrm{M1}_{0.98}-\mathrm{CO}-\mathrm{M2}_{0.02}\right) / \mathrm{Ba}^{2+}$, easily visualized by the formation of new bigger aggregates, (Figure 5$)^{45}$ shown to be nanospheres with a size that depend on the amount of thiolated group in the copolymer and Barium added.

Thus, particles with average hydrodynamic diameter size of 482 and $534 \mathrm{~nm}$ are obtained when Au-poly-( $\mathrm{M1}_{0.99}-\mathrm{CO}-$ $\mathrm{M2}_{0.01}$ ) is treated with 0.2 and 0.4 equiv. of $\mathrm{Ba}^{2+}$ respectively, while particles with 366 and $420 \mathrm{~nm}$ result when 0.2 and 0.4 equiv. of $\mathrm{Ba}^{2+}$ are added to Au-poly( $\mathrm{M} 1_{0.98}-\mathrm{CO}-\mathrm{M} \mathbf{2}_{0.02}$ ).

For its part, in the case of the composites with larger thiolated contain, $\mathrm{Au}-$ poly-( $\left.\mathrm{M1}_{0.97}-\mathrm{CO}-\mathrm{M} \mathbf{2}_{0.03}\right)$, Au-poly( $\left.\mathbf{M 1}_{0.96}-\mathrm{CO}-\mathrm{M2}_{0.04}\right)$ and Au-poly-(M1 $\left.1_{0.95}-\mathrm{CO}-\mathrm{M} \mathbf{2}_{0.05}\right)$-, the addition of $\mathrm{Ba}^{2+}$ solution had no impact on the original fibers neither in the gel probably due to the already compact structure of the starting materials (See ESI). 
Thiol \% in copolymer

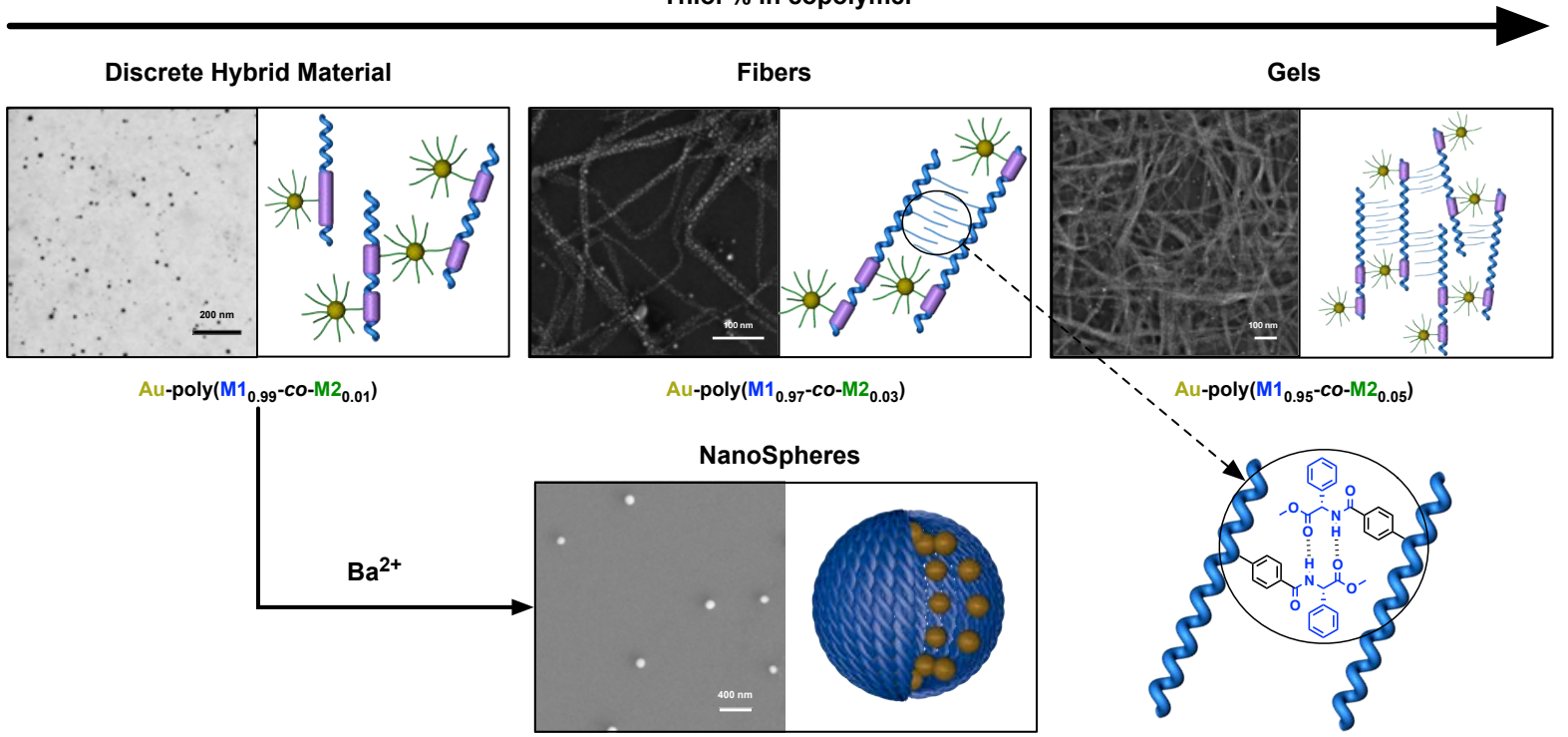

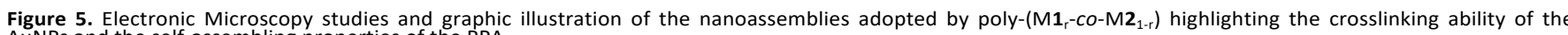
AuNPs and the self-assembling properties of the PPA.

\section{Conclusions}

In conclusion, we have studied the role of a macromolecular helical structure in the formation of a helical polymer-Au nanocomposite. To perform these studies a poly(phenylacetylene) bearing the benzamide of a phenylglyicine methylester (M1) as pendant group was chosen.

This selection was done based on our knowledge in the structure and dynamic behavior of the polymer. To form the nanocomposite, a thiolated monomer was introduced in the polymer chain. This thiolated monomer has a structural effect on the copolymer secondary structure and its dynamic behavior before and after the formation of the hybrid material.

Thus, the introduction of the thiolated comonomer in the copolymer chain destabilize the helical arrangement of the M1 monomers placed close to this residue. Interestingly, we found that the thiol groups should be located in nearby positions, because the depletion of the helix folding it is not further affected by increasing the amount of the thiol group in a molar fraction range of 0.01-0.05.

Additionally, hybridization of these thiolated copolymers with AuNPs produces another perturbation in the polymeric secondary structure, although its dynamic behavior it is not affected, being possible to modulate the nanocomposite chirality by the action of external stimuli such as solvent polarity.

Next, we found that the morphology of the nanocomposites can be modulated through the thiolated monomer ratio within the copolymer chain. Thus, at the lowest thiolated molar fraction (0.01), the nanocomposite appears as dispersed AuNPs in electron microscopy. Interestingly, at higher molar ratios of the thiolated monomer, the controlled formation of fiber like structures is produced by combining the crosslinking ability o of the AuNPs with the self-assembly properties of the copolymer. Finally, a further controlled self-assembly of a nanocomposite was achieved by using metal ions $\left(\mathrm{Ba}^{2+}\right)$ as crosslinking agents. Thus, in the case of Au-poly-( $\mathrm{M1}_{0.98^{-}} \mathrm{CO}-$ $\left.\mathrm{M} 2_{0.02}\right)$ and Au-poly-(M1 $\left.1_{0.99}-\mathrm{Co}-\mathrm{M} \mathbf{2}_{0.01}\right)$ it was possible to generate macroscopically chiral nanospheres, whose size could be controlled by tuning the nanocomposite/ $\mathrm{Ba}^{2+}$ ratio.

Therefore, a first insight into the control over the chiral dynamicity of plasmonic nanocomposites was demonstrated. Notably, a first controlled assembly into different nanomorphologies was achieved by considering the thiol comonomer content and the helix-to-helix supramolecular interactions. Besides, by using metal ions as crosslinking agents, some of these morphologies are further nanostructured into macroscopically chiral nanospheres with low polydispersity.

\section{Conflicts of interest}

There are no conflicts to declare. 


\section{Acknowledgements}

We thank Servicio de Microscopía Electrónica (RIAIDT, USC). Financial support from MINECO (CTQ2015-70519-P), Xunta de Galicia (ED431C 2018/30, Centro singular de investigación de Galicia accreditation 2016-2019, ED431G/09) and the European Regional Development Fund (ERDF) is gratefully acknowledged. M. N.-M. thanks MICINN for a FPI contract (BES-2016-078107).

\section{Notes and references}

1 S. Zhang, R. Geryak, J. Geldmeier, S Kim, S. V. Tsukruk, Chem. Rev. 2017, 117, 12942.

2 M. Molina, M. Asadian-Birjand, J. Balach, J. Bergueiro, E. Miceli, M. Calderon, Chem. Soc. Rev., 2015, 17, 6161.

3 G. Zheng, Z. Bao, J Pérez-Juste, D. Ruolan, W. Liu, J Dai, W. Zhang, L Lee, K-Y. Wong, Angew. Chem. Int. Ed., 2018, 57, 16452.

4 X. Lu, D.-P. Song, A. Ribbe, J. Watkings, Macromolecules, 2017, 50, 5293.

5 Y. Zhou, H. Sun, S. Matysiak, J Ren, X. Qu, Angew. Chem. Int. Ed., 2018, 57, 16791.

6 Y.-L. Lin, J. L. Chu, H. J. Lu, N. Liu, Z. Q. Wu, Macromol. Rapid Commun., 2018, 39, 1700685.

7 D. Liu, H. Chen, J. Deng, W. Yang, J. Mater. Chem. C, 2013, 1, 8066

8 E. Dreaden, A. Alkilany, X. Huang, C. Murphy, M. ElSayed, Chem. Soc. Rev., 2012, 41, 2740.

9 M. Fleischmann, P. Hendra, A. McQuillan, Chem. Phys. Lett. 1974, 26, 163

10 L. Kvítek, R. Prucek, A. Panácek, A. Novotny, J. Hrbác, R. Zoboril, J. Mat. Chem., 2005, 15, 1099.

11 K. Faulds, W. Ewen Smith, D. Graham, Anal. Chem. 2004, 76, 412.

12 D. Jaque, L. Martínez Maestro, B. del Rosal, P. HaroGonzalez, A. Benayas, J. Plaza, E. Martín Rodriguez, García Solé, Nanoscale, 2014, 6, 9494.

13 J. Chen, C. Glaus, R. Laforest, Q. Zhang, M. Yang, M. Gidding, M. Welch, Y. Xia, Small, 2010, 6, 811.

14 A. Lee, G. Andrade, A. Ahmed, M. Souza, N. Coombs, E. Turmarkin, K. Liu, R. Gordon, A. Brolo, E. Kumacheva, J. Am. Chem. Soc., 2011, 133, 7563.

15 P. Pramod, K. Thomas, Adv. Mat., 2008, 20, 4300.

16 J. M. Abad, S. F. Mertens, M. Pita, V. M. Fernández, D. J. Schiffrin, J. Am. Chem. Soc., 2005, 127, 5689.

17 P. Taladriz-Blanco, N. Buurma, L. Rodríguez-Lorenzo, J. Pérez-Juste, L. Liz-Marzán, P. Hervés, Mat. Chem., 2011, 21, 16880.

18 J. Ou, H. Tan, X. Chen, Z. Chen, Nanomaterials, 2018, 8, 994.

19 C. Zhang, C. Song, W. Yang, J. Deng, J. Macromol. Rapid Commun., 2013, 34, 1319.

20 L. Zhu, X. Li, S. Wu, K. T. Nguyen, H. Yan, H. Ågren, Y. Zhao, J. Am. Chem. Soc. 2013, 135, 9174.

21 E. Yashima, K. Maeda, Y. Furusho, Acc. Chem. Res., 2008, 41, 1166.

22 E. Yashima, K. Maeda, H. Lida, Y. Furusho, K. Nagai, Chem. Rev. 2009, 109, 6102.

23 J. Liu, J. W. Lam, B. Z. Tang, Chem. Rev., 2009, 109, 5799.

24 B. M. Rosen, C. J. Wilson, D. A. Wilson, M. Peterca, M. R. Imam, V. Percec, Chem. Rev. 2009, 109, 6275.

25 E. Schwartz, M. Koepf, H. J. Kito, R. J. M. Nolte, A. E. Rowan, Polym. Chem. 2011, 2, 33.
26 F. Freire, E. Quiñoá, R. Riguera, Chem. Commun., 2017, 53, 481.

27 T. Van Leeuwen, H. G. Heideman, D. Zhao, S. J. Wezenberg, B. L. Feringa, Chem. Commun., 2017, 53, 6393.

28 S. Wang, J. Chen, X. Feng, G. Shi, J. Zhang, X. Wan, Macromolecules, 2017, 50, 4610.

29 F. Freire, E. Quiñoá, R. Riguera, Chem. Rev., 2016, 116, 1242.

30 F. Freire, J. M. Seco, E. Quiñoá, R. Riguera, Adv. Polym. Sci., 2013, 262, 123

31 E. Yashima, Polymer Journal, 2010, 42, 3.

32 E. Yashima, K. Maeda, Macromolecules, 2008, 41, 3.

33 V. Percec, J. G. Rudick, M. Peterca, P. A. Heiney, J. Am. Chem. Soc., 2008, 130, 7503

34 J. Lam, B. Z. Tang, Acc. Chem. Res., 2005, 38, 745.

35 S. Arias, F. Freire, E. Quiñoá, R. Riguera. Polym. Chem., 2015, 6, 4725.

36 S. Arias, M. Núñez-Martinez, E. Quiñoá, R. Riguera, F. Freire, Polym. Chem, 2017, 8, 3740.

37 R. Rodríguez, S. Arias, E. Quiñoá, R. Riguera, F. Freire, Nanoscale, 2017, 8, 17752.

38 E. Suárez-Picado, E. Quiñoá, R. Riguera, F. Freire, Chem. Mater., 2018, 30, 6908.

39 R. Rodríguez, E. Quiñoá, R. Riguera, F. Freire, Chem. Mater., 2018, 30, 2493.

40 S. Arias, F. Freire, M. Calderón, J. Bergueiro, Angew. Chem. Int. Ed. 2017, 56, 11420.

41 R. Rodríguez, E. Quiñoá, R. Riguera, F. Freire, J. Am. Chem. Soc., 2016, 138, 9260.

42 M. Brust, V. Walker, D. Bethell, D. J. Schiffrin, R. J. Whyman, Chem. Soc. Chem. Commun., 1994, 801.

43 M. Alzubi, S. Arias, I. louzao, E. Quiñoá, R. Riguera, F. Freire, Chem. Commun., 2017, 53, 8573.

44 B. Fernandez, R. Rodríguez, A. Rizzo, E. Quiñoá, R. Riguera, F. Freire, Angew. Chem. Int. Ed., 2018, 57, 3666.

45 F. Freire, J. M. Seco, E. Quiñoá, R. Riguera, J. Am. Chem. Soc., 2012, 134, 19374. 
TOC
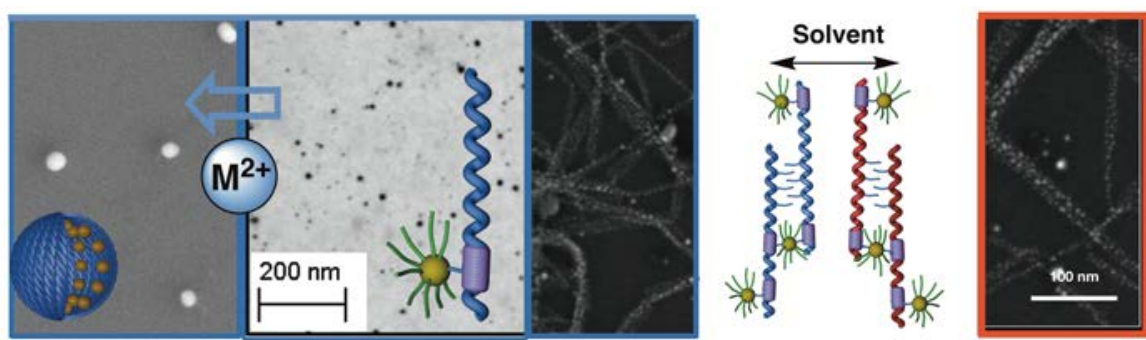